\title{
Spatial and temporal expression patterns of lolitrem biosynthetic genes in the Epichloë festucae-perennial ryegrass symbiosis
}

\author{
K.J.MAY, M.K. BRYANT, X. ZHANG, B. AMBROSE, B. SCOTT \\ Centre for Functional Genomics, Institute of Molecular BioSciences, Massey University, Private Bag 11 222, Palmerston North, \\ New Zealand \\ k.may@massey.ac.nz
}

Epichloë festucae systemically colonises the intercellular spaces of perennial ryegrass (Lolium perenne) aerial tissues forming a mutually beneficial association between the fungus and host plant. In association with its host grass, E. festucae synthesises a range of indole-diterpenes, including lolitrem $\mathrm{B}$, which provide protection to the symbiotum against small animal herbivory. A gene cluster of at least ten ltm (lolitrem) genes is required for lolitrem B biosynthesis (Young et al. 2005; Young et al. 2006). RT-PCR analysis of RNA derived from mycelium and pseudostem tissue suggest that these genes are expressed only when the fungus is in association with the grass host (Young et al. 2006). The objectives of this study were, first, to test if $l$ tm genes were subject to carbon and/or nitrogen catabolite repression, and secondly to examine the expression patterns of the ltm genes in planta using GUS reporter gene analysis.

The expression of the 10 E. festucae ltm genes was examined by reverse transcriptase (RT)-PCR analysis using RNA template derived from mycelium grown under a range of physiological conditions, including both $\mathrm{N}$ - and C-repressed and -derepressed conditions. While transcript could be detected for most genes under nearly all conditions tested, the level of transcript, with the exception of $\operatorname{ltm} K$, was very low compared to transcript levels found in planta. These results demonstrate that $l$ tm gene expression is not subject to either $\mathrm{N}$ or C-catabolite repression.

The ltm $M$ gene, which encodes an enzyme for an early step in the lolitrem biosynthetic pathway, was selected to examine the patterns of $\mathrm{ltm}$ gene expression in planta. Five different ltmM promoter deletion fragments were generated, translationally fused to gusA and transformed into E. festucae protoplasts. The minimum promoter length required for gus $A$ expression in planta was found to be $800 \mathrm{bp}$. In mature vegetative tillers, gusA was expressed in all infected aerial plant tissues, including epiphyllous hyphae. The gusA expression pattern of the positive control, a Pgpd-gusA transformant, was similar to the PltmM-gusA transformants, confirming that $\mathrm{ltm} M$ is expressed at all times in vegetative tillers. At pre-anthesis, gusA expression was observed in all floral organs except the immature gynoecium. Similar GUS activity patterns were observed in control plants, except the ovule was colonised, with hyphae restricted to the nucellar tissue. In post-anthesis florets, gene expression occurred almost exclusively in the anthers and the gynoecium with dense staining observed in the stigma. In contrast, for the control plants, GUS activity was observed in all tissues of the spikelet. In germinating seedlings PltmM expression was observed in hyphae $24 \mathrm{~h}$ postgermination in seeds and $6 \mathrm{~d}$ post-germination in seedlings, from the mesocotyl to the tip of the emerging first leaf. These results suggest that during seed germination hyphae in the shoot apex have a significant role in further colonisation of the seedling.

\section{REFERENCES}

Young, C.A.; Bryant, M.K.; Christensen, M.J.; Tapper, B.A.; Bryan, G.T.; Scott, B. 2005. Molecular cloning and genetic analysis of a symbiosis-expressed gene cluster for lolitrem biosynthesis from a mutualistic endophyte of perennial ryegrass. Molecular Genetics and Genomics 274: 13-29.

Young, C.A.; Felitti, S.; Shields, K.; Spangenberg, G.; Johnson, R.D.; Bryan, G.T.; Saikia, S.; Scott, B. 2006. A complex gene cluster for indole-diterpene biosynthesis in the grass endophyte Neotyphodium lolii. Fungal Genetics and Biology 43: 679-693. 